\title{
Ensino da prototipagem rápida e fabricação digital para arquitetura e construção no Brasil: definições e estado da arte
}

The learning processes of rapid prototyping and digital fabrication in architecture and building in Brazil: definitions and state of the art

\section{REGIANE TREVISAN PUPO}

Arquiteta, graduada em Arquitetura e Urbanismo pela Faculdade de Arquitetura e Urbanismo da Pontifícia Universidade Católica de Campinas, mestre em Engenharia de Produção pelo Programa de Pós- Graduação em Engenharia de Produção da Universidade Federal de Santa Catarina, doutoranda em Engenharia Civil pelo Programa de Pós-Graduação em Engenharia Civil da Universidade Estadual de Campinas, professora dos Departamentos de Arquitetura e Design Industrial da Universidade do Vale do Itajaí.

rpupo@fec.unicamp.br

\section{Resumo}

Os objetivos deste artigo são: (1) o de apresentar o estado da arte da prototipagem rápida e fabricação digital para a arquitetura e construção, (2) identificar como o impacto das novas tecnologias atua na pesquisa e no ensino de arquitetura no Brasil hoje e (3) relatar algumas experiências didáticas desenvolvidas no Laboratório de Automação e Prototipagem para Arquitetura e Construção da Faculdade de Engenharia Civil, Arquitetura e Urbanismo - FEC, da Unicamp.

Palavras-chave: prototipagem rápida; fabricação digital; processo de projeto; ensino com novas tecnologias.

\begin{abstract}
The objectives of the present paper are: (1) to present the state of the art in rapid prototyping and digital fabrication for architecture and construction, (2) to identify how the impacts of new technologies act in architecture learning processes and researches in Brazil today, and (3) to show some experiences developed at LAPAC - the Automation and Prototyping for Architecture and Construction Laboratory of the School of Civil Engineering, Architecture and Urban Design of the University of Campinas.
\end{abstract}

Keywords: rapid prototyping; digital fabrication; design process; learning with new technologies 
Ensino da prototipagem rápida e fabricação digital para arquitetura e construção no Brasil: definições e estado da arte

\section{Introdução}

A inovação tecnológica que as áreas de projeto e indústria da construção civil têm alcançado nas últimas décadas se deve, em grande parte, ao rápido desenvolvimento da indústria da computação. Ela tem introduzido novas técnicas, estabelecido novos desafios e criado novas ferramentas na rotina dos arquitetos. Mais recentemente, tornou-se possível utilizar modelos geométricos digitais diretamente para a produção de artefatos físicos, desde maquetes em escala e protótipos em tamanho real até peças finais. Na área de arquitetura e construção, hoje, o processamento tridimensional tem se tornado processo padrão em vários procedimentos, fazendo da prototipagem rápida e da fabricação digital grandes aliadas dos novos desafios projetuais. Um dos principais benefícios do desenvolvimento cada vez maior de seu uso é a opção de ter a visualização como grande colaboradora da compreensão espacial, bem como complemento e caminho para a confecção de modelos rapidamente prototipados. Essa nova possibilidade tem causado um enorme impacto desde o início do processo de projeto do edifício até a sua construção (MITCHELL e McCULLOUGH, 1995), contribuindo para mudanças na forma de projetar e em sua produção, automatizando tarefas e introduzindo novas tecnologias.

A diferença entre os novos métodos de produção baseados em modelos digitais e os antigos métodos de produção de massa é que eles não se destinam a produzir cópias idênticas de um mesmo produto. Pelo contrário, constituem-se em sistemas suficientemente adaptáveis para produzir um grande espectro de formas diferentes. Esse novo conceito tem sido chamado de "mass customization" (personalização em massa), e foi definido por autores como Stan Davis (1996), Tseng e Jiao (2001), Pine (1993), e Kaplan e Haenlein (2006). Na arquitetura, o termo foi usado, por exemplo, por José Pinto Duarte, em sua tese de doutorado intitulada "Customizing Mass Housing: a discursive grammar for Siza's houses at Malagueira" (2001). Contudo, segundo Schodek et al. (2005),

paradigmas tradicionais que têm há muito tempo caracterizado as atitudes fundamentais de projeto, tais como a necessidade de estandardização e repetição no projeto de componentes construtivos para que se possa aproveitar eficientemente as técnicas industriais de produção 


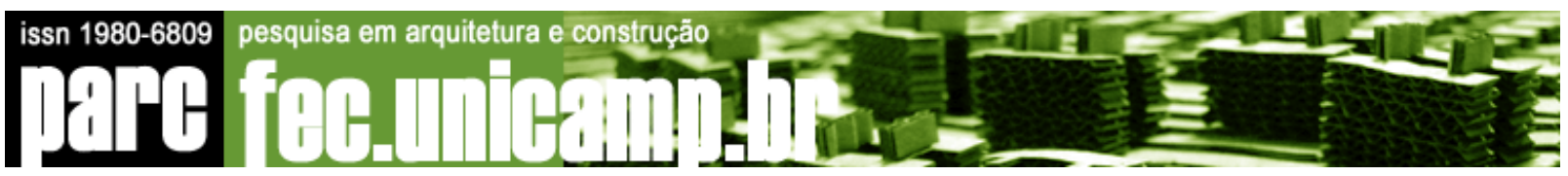

estão sendo desafiadas pela customização em massa e outras idéias que se tornaram factíveis por meio de novos métodos de projeto e produção (p.ix).

Como resultado, existe uma crescente atenção entre arquitetos e estudantes de arquitetura sobre as potencialidades da produção individualizada dos elementos construtivos dentro da composição e percepção arquitetônicas. Neste contexto, os ambientes acadêmicos devem estar preparados para responder ao desafio de dar os primeiros passos com iniciativas que sejam benéficas e que estimulem experiências de aprendizado. Ao mesmo tempo, é necessária a instalação de laboratórios com nível de inovação técnica, além de grupos de estudo em ambientes educacionais que possam oferecer oportunidades de conectar a pesquisa, disciplinas práticas e a prática profissional.

As escolas de arquitetura têm tentado incorporar cada vez mais as tecnologias CAD Computer Aided Design em disciplinas de projeto. No Brasil, essas tecnologias têm sido introduzidas isoladamente, muitas vezes como cursos extracurriculares, com o objetivo de dar ao aluno uma base simples para a futura inserção no mercado de trabalho. Já em países da Europa, algumas escolas vêm tentando intensa integração dos computadores com o atelier de projeto. Além das tecnologias CAD, mais recentemente, a prototipagem rápida e a fabricação digital têm tido considerável importância dentro dos cursos de arquitetura, principalmente no exterior, numa crescente busca na integração projeto/obra. Segundo Mark et al. (2000), o currículo considerado ideal seria aquele que traz a tecnologia do computador para dentro de cursos já existentes, gradativamente, ao mesmo tempo que olhe para os métodos de ensino de projeto, como um catalisador na mudança de perspectivas nas áreas relevantes da metodologia e teoria de projeto. Para que se compreenda como e porque essa inserção deve ser incorporada à grade curricular de cursos de arquitetura, é necessário que as definições e constantes atualizações a respeito do estado da arte dessas novas tecnologias sejam identificadas.

\section{Definições}

Os novos métodos de produção não são mecânicos, mas controlados por computadores. Daí o nome Computer Numeric Control, ou CNC, normalmente associado às fresas de controle numérico. O termo prototipagem rápida (rapid prototyping) refere-se normalmente aos métodos de produção de protótipos por sistemas aditivos (BUSWELL et al., 2007). Contudo, existem também métodos baseados na sobreposição de camadas 


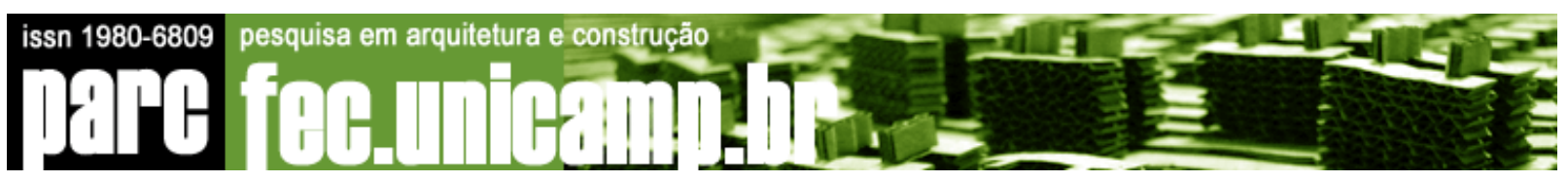

destinados à produção de produtos finais. Esses métodos são conhecidos como manufatura rápida (rapid manufacturing). O termo rapid, em ambos os casos (rapid prototyping e rapid manufacturing), faz referência ao fato desses sistemas não requererem nenhum tipo de assistência humana.

Os métodos de produção automatizada utilizados na arquitetura e construção podem ser categorizados segundo (1) sua finalidade, (2) o número de eixos com que trabalham e (3) a maneira como produzem os objetos. A FIG. 1 ilustra cada uma dessas categorias e todas as possíveis utilizações na área de arquitetura e construção civil. Suas aplicações podem variar desde a produção de maquetes de estudo para o apoio ao processo de projeto até a construção de edifícios inteiros, passando pela elaboração de elementos construtivos, construídos e enviados diretamente para a obra.

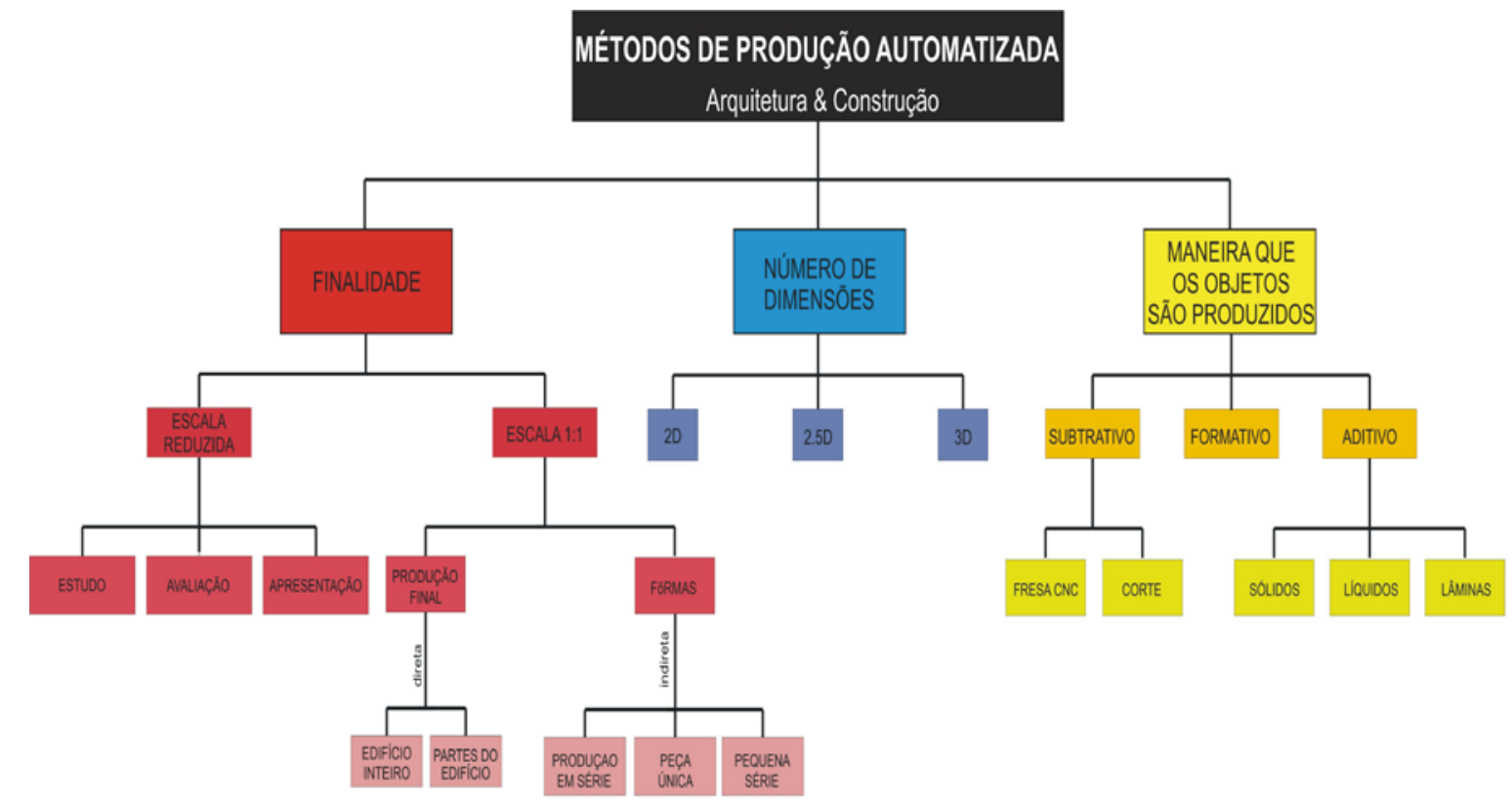

FIGURA 1: Métodos de produção automatizada para Arquitetura e Construção

No que se refere à sua finalidade, eles podem ser destinados à produção de modelos em escala reduzida ou à produção de produtos finais, em escala 1:1, para serem empregados diretamente na obra. Em geral, os primeiros são conhecidos como métodos de prototipagem (prototyping), e podem ser utilizados para estudos iniciais, para avaliações de projeto ou para apresentações finais. A FIG. 2 ilustra um estudo de elementos de fachada do projeto Der Neue Zollhof, em Dusseldorf, Alemanha, de 2000, do arquiteto Frank O. Gehry, 


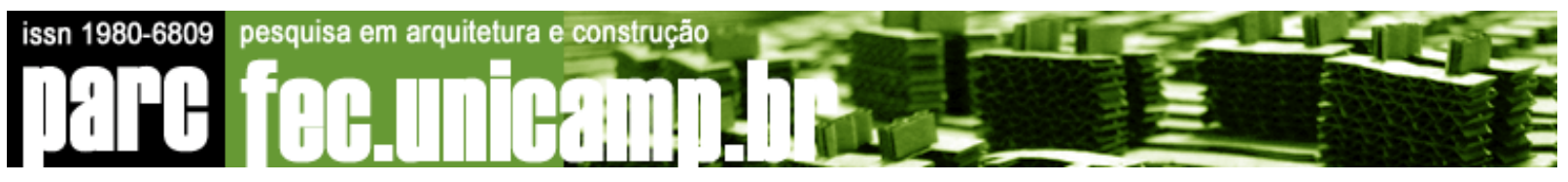

com a ajuda da prototipagem rápida. A partir de um modelo digital, a peça é testada em um modelo físico, prototipado, podendo ser reajustado, e o resultado final é um modelo digital da fachada com o detalhe do elemento construtivo escolhido.

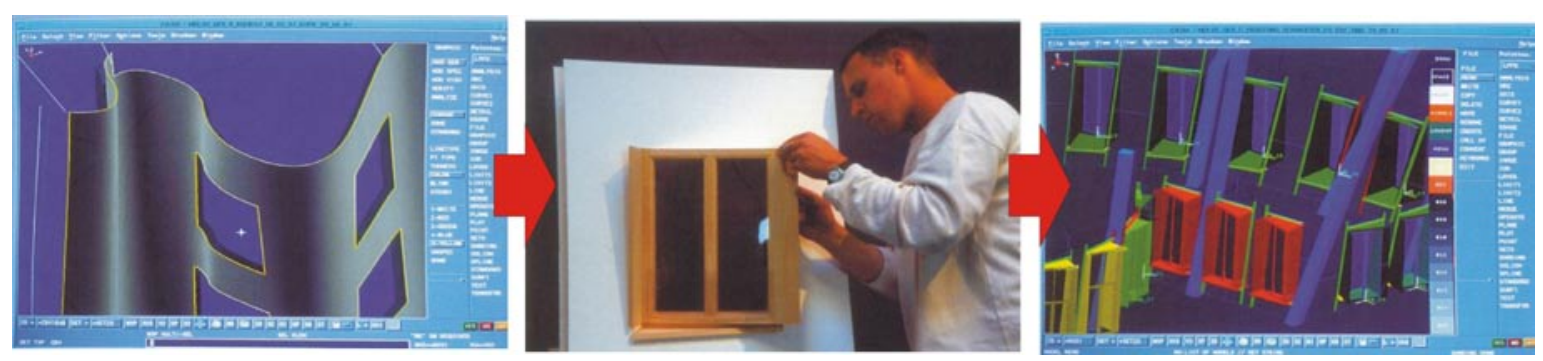

FIGURA 2: Estudo de um elemento de fachada. Projeto Der Neue Zollhof, Dusseldorf, Alemanha, 2000, Frank O. Gehry

Fonte: Schmal (2001, pp. 99)

Para a produção final desses elementos construtivos, em escala real, são utilizados os sistemas de fabricação (fabrication) ou de manufatura (manufacturing), podendo ser destinados à produção de fôrmas a serem utilizadas na obra. A FIG. 3 mostra, em nove etapas, o processo de fabricação digital do mesmo elemento construtivo do projeto Der Neue Zollhof, descrito acima. Desde sua concepção até a colocação na obra, cada elemento construtivo, nesse caso um painel de fachada, é produzido individualmente, com moldes em isopor "esculpidos" por uma fresa CNC, a partir de um modelo 3D digital. Posteriormente, o revestimento, que consiste de material isolante e aço inoxidável, é aplicado definindo a espessura das paredes de concreto.

1. Concepção da forma arquitetônica;

2. Construção do molde, em poliestireno, do elemento construtivo em fresa CNC;

3. Preparação do molde para a aplicação de concreto;

4. Aplicação da ferragem e concretagem;

5. Acabamento;

6. Desmoldagem;

7. Elementos construtivos prontos para serem inseridos na obra;

8. Localização dos elementos construtivos;

9. Finalização. 

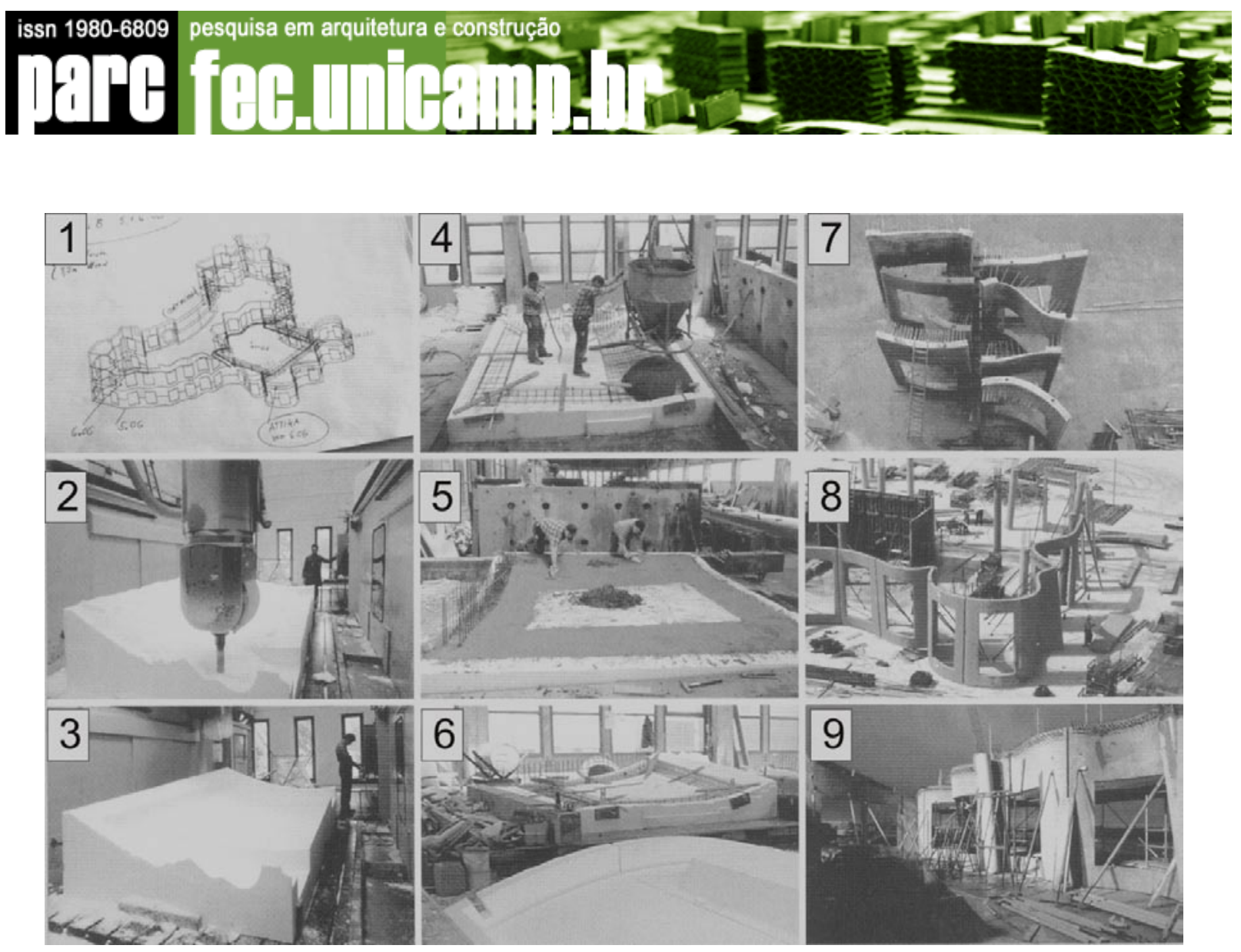

FIGURA 3: Processo de fabricação digital - Der Neue Zollhof, de Frank Gehry, Dusseldorf, Alemanha, 2000 Fonte: (SCHMAL, 2001).

A outra possibilidade do método em escala 1:1 é a produção final do edifício, com a construção automatizada, sem utilização de mão-de-obra humana. O processo, chamado de "Contour Crafting" (FIG. 4) foi desenvolvido pelo professor de engenharia industrial Dr. Behrokh Khoshnevis, da Universidade do Sudeste da Califórnia. É uma tecnologia de fabricação por camadas que tem um grande potencial na construção automatizada de toda a estrutura. Uma simples casa, ou uma colônia de casas, com a possibilidade de diferentes desenhos, podem ser automaticamente construídas com instalações elétricas, hidráulicas e ar condicionado, permitindo que arquitetos projetem estruturas com geometrias complexas e difíceis de executar. (KHOSHNEVIS, 2004). 

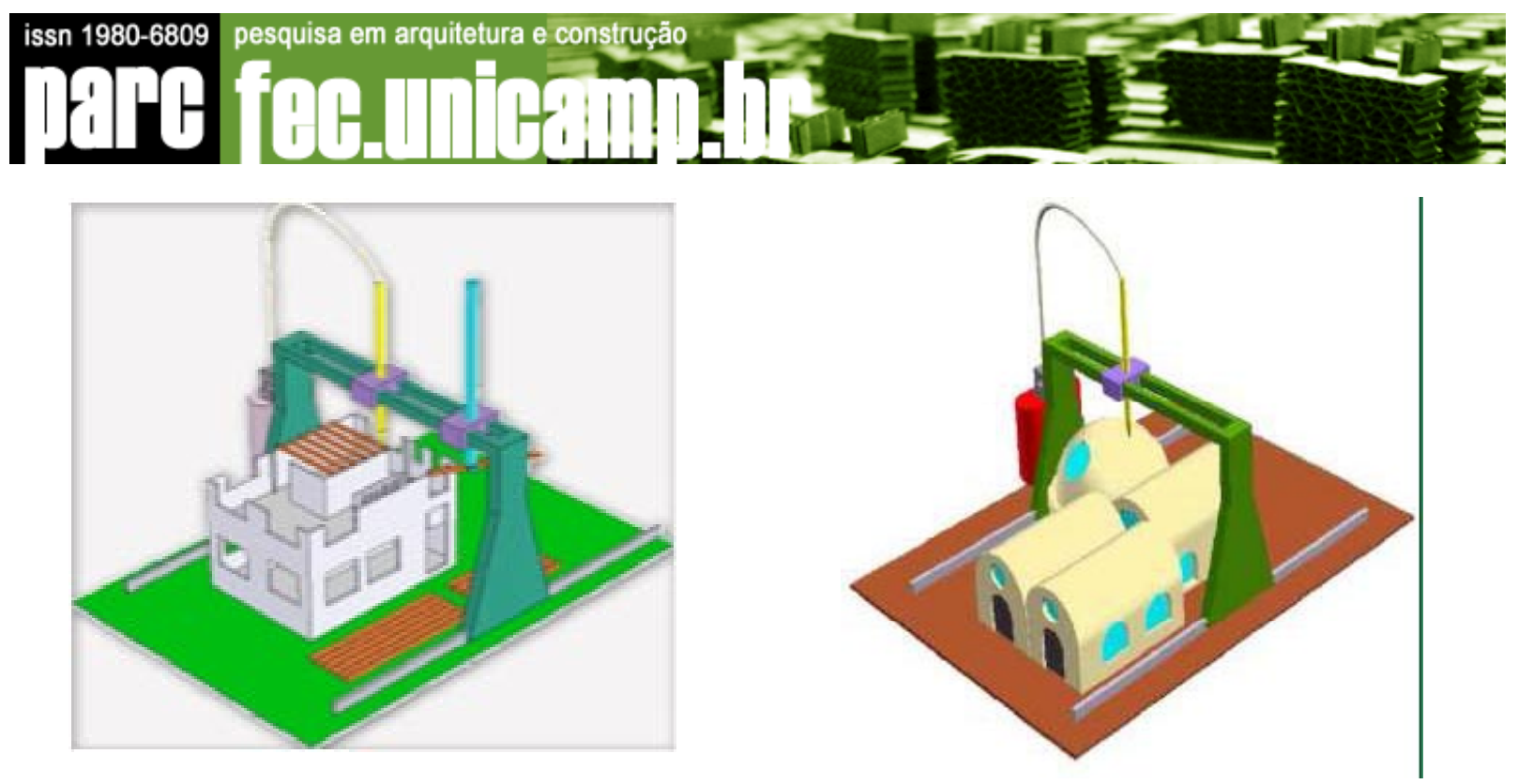

FIGURA 4 - Contour Crafting (KHOSHNEVIS, 2004)

Quanto ao número de dimensões, esses sistemas possuem tipicamente duas dimensões (2D), duas dimensões e meia (2.5D) e três dimensões (3D). Um exemplo de sistema de duas dimensões é a cortadora de vinil, que corta apenas papel ou outros materiais finos. Uma fresa de controle numérico com um spindle (eixo) pode cortar figuras planas e executar relevos, porém não é capaz de produzir modelos tridimensionais complexos. Por esse motivo esse tipo de equipamento é freqüentemente chamado de 2.5D. É o caso da Modela MDX-40, da empresa Roland (FIG. 5).
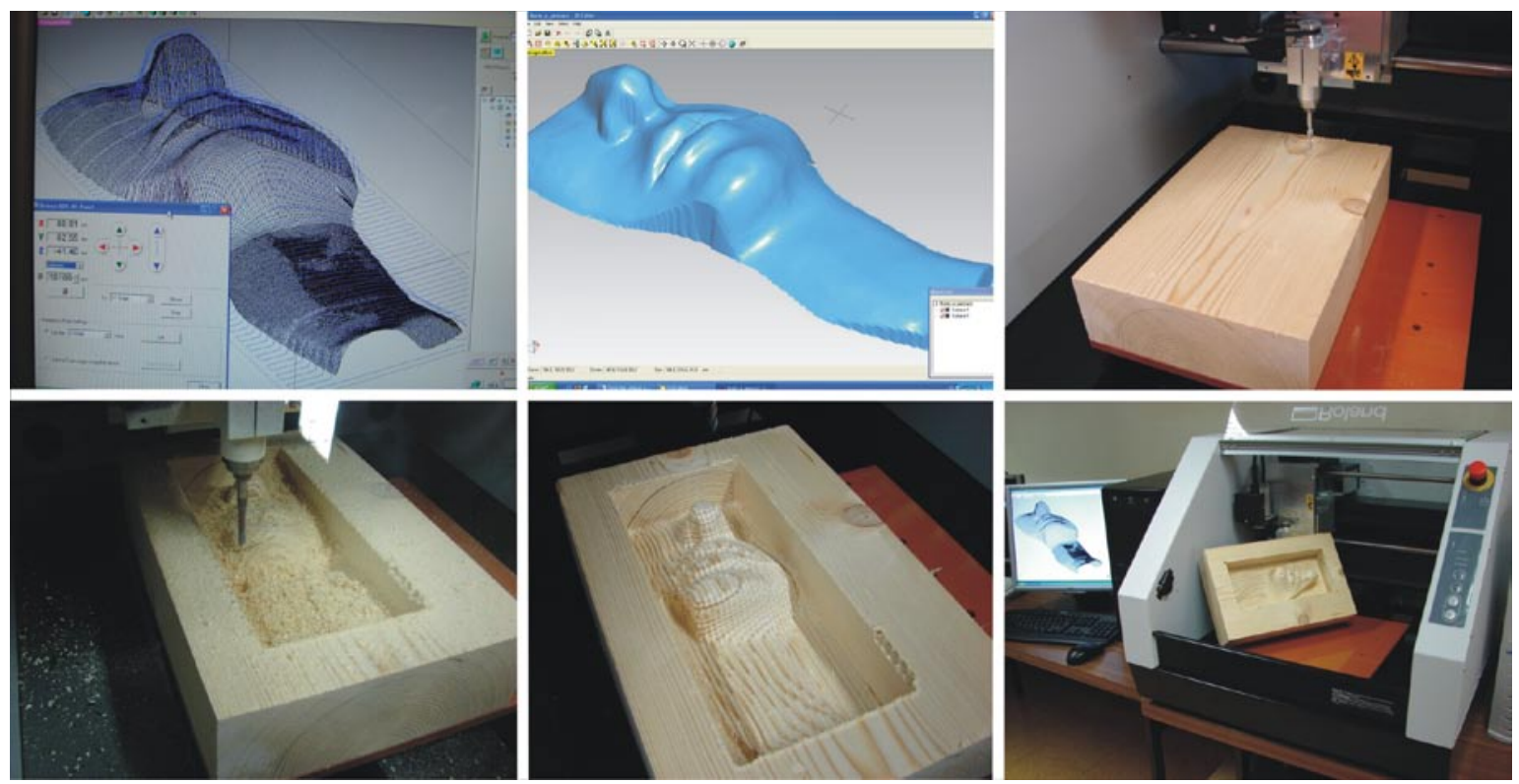

FIGURA 5: Fresagem em 2.5 dimensões Fotos: Regiane Pupo 


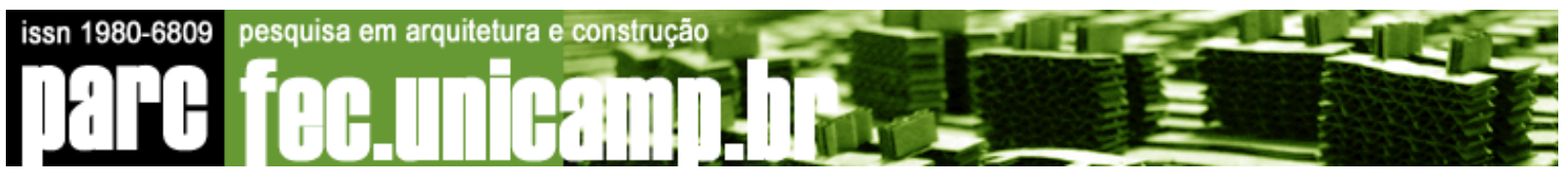

Já as fresas de três, quatro ou cinco eixos (FIG. 6) ou um sistema de impressão 3D (FIG. 7) são considerados efetivamente tridimensionais.

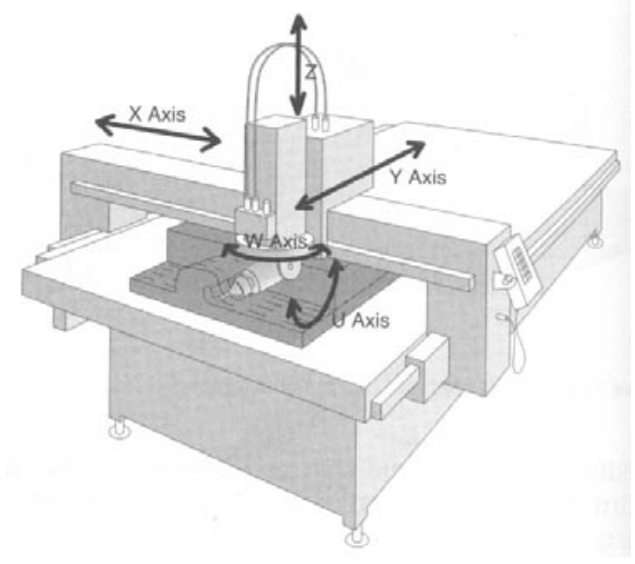

FIGURA 6: Fresagem com 5 eixos Fonte: Shodek (2005, pp. 242)

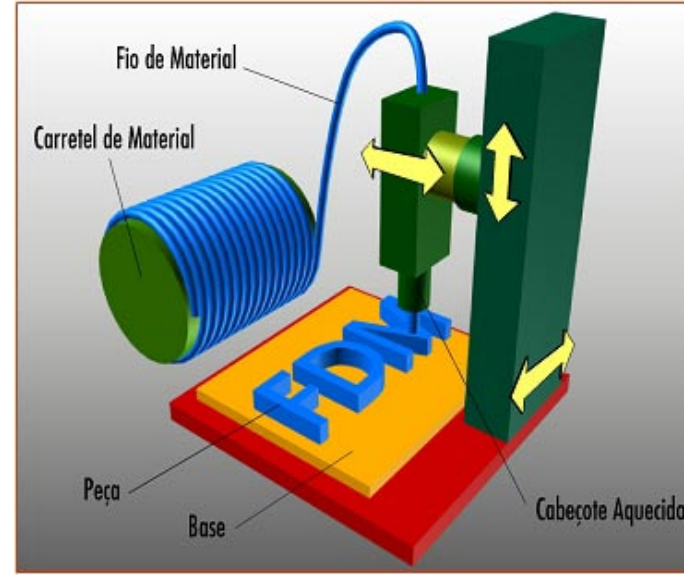

FIGURA 7: Impressão 3D em FDM Fonte: INT/MCT

Sobre a maneira que os objetos são produzidos, os métodos automatizados podem ser do tipo subtrativo, formativo ou aditivo. No sistema subtrativo, duas soluções de desbaste de material são utilizadas: (1) as fresas CNC e (2) os sistemas de corte. No primeiro, um bloco de material é desbastado seletivamente por fresas que se movem automaticamente em diversas direções (de 1 a 5 eixos), ou ainda com o auxílio de um eixo rotatório que movimenta o bloco para diminuir a necessidade de deslocamento da peça. Esse sistema de produção é muito utilizado em indústrias de ferramentaria, permitindo a produção precisa de moldes e peças usinadas a partir de blocos de metal (FIG. 8).
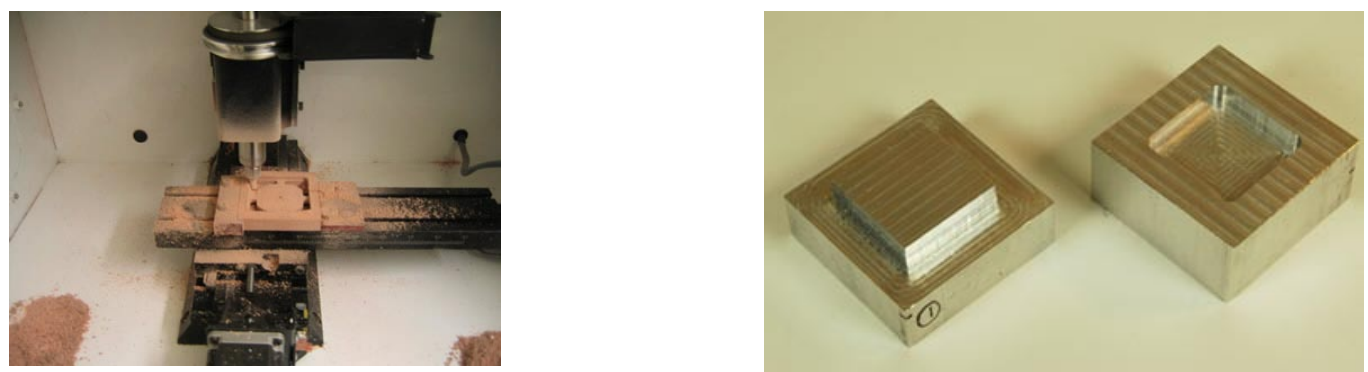

FIGURA 8: Produção de peças de metal pelo método subtrativo

O segundo sistema subtrativo, o de corte, inclui as cortadoras a laser, as jato d’água e as plasma-arc. Caracterizam-se pelos movimentos bidimensionais do eixo de corte, do material a ser cortado ou uma combinação dos dois. Entretanto, existem grandes diferenças entre estas tecnologias devido ao material e espessuras utilizadas. A cortadora Plasma-arc, 


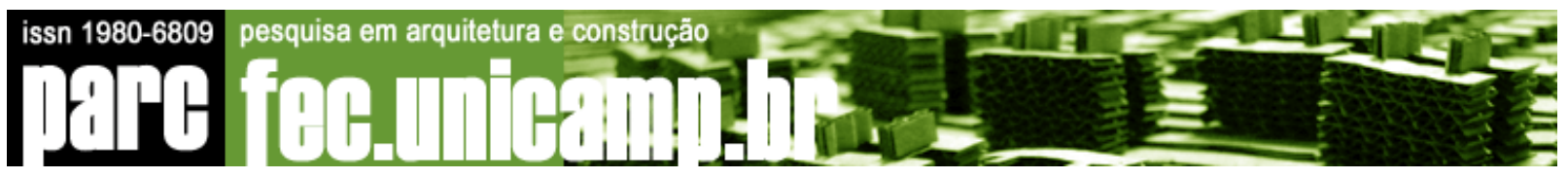

por exemplo, utiliza um arco elétrico e gás comprimido com uma temperatura de quase 14.000 graus celcius no momento do corte. Enquanto a cortadora laser corta materiais com até $16 \mathrm{~mm}$ de espessura, as de jato d'água tem capacidade de corte, por exemplo, de uma placa de titânio de $38 \mathrm{~cm}$ de espessura. Esses são em geral chamados genericamente de sistemas de fabricação digital (digital fabrication) e suas aplicações na arquitetura e construção são as mais variadas, desde a produção de fôrmas para concreto armado, como visto acima, até a produção de ornamentos esculpidos em pedra que podem ser utilizados, por exemplo, como "próteses" arquitetônicas em obras de restauro.

O sistema formativo assemelha-se a um molde versátil, com a capacidade de se adaptar a diferentes formas. Um exemplo desse sistema são os moldes adaptáveis para a produção de placas de vidro com curvaturas especiais. Esses moldes podem ser feitos, por exemplo, com um sistema de pinos de alturas reguláveis, que são posicionados automaticamente a partir de informações obtidas do modelo digital da superfície que se pretende reproduzir. Após o ajuste dos pinos, uma placa plana de vidro é colocada sobre o molde e levada a um forno, onde ela derrete e assume a configuração da base de pinos. Outro exemplo são os equipamentos que permitem dobrar e encurvar chapas de aço e tubos metálicos a partir de um modelo digital, como aplicado no projeto do BMW Pavilion, em Frankfurt, Alemanha, de Bernard Franken, em 2000 (FIG. 9).
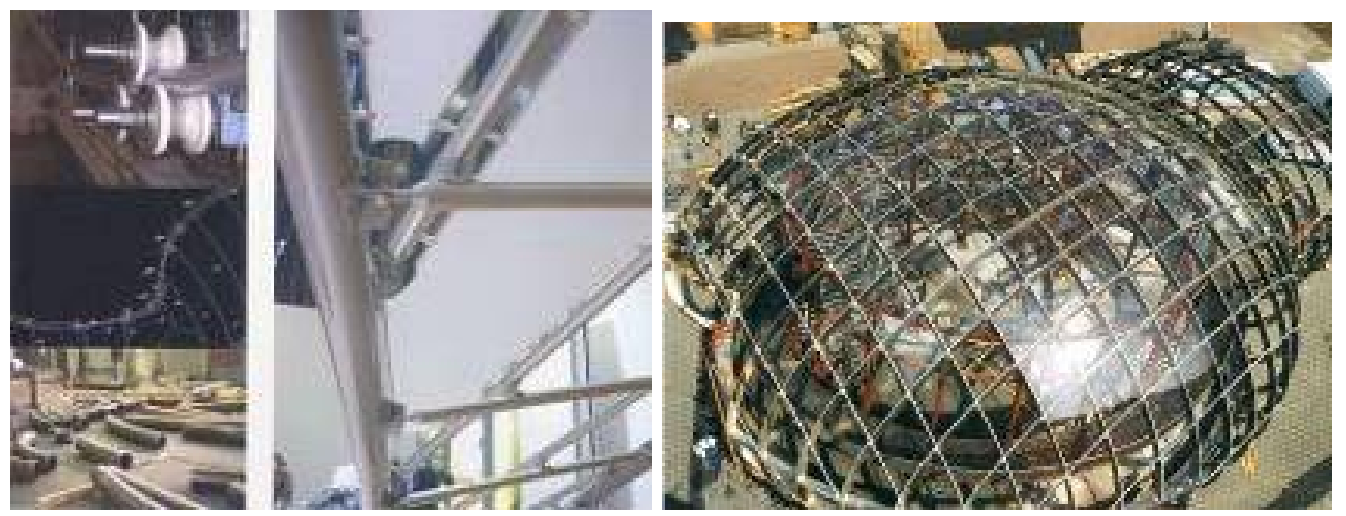

FIGURA 9: Sistema formativo - BMW Pavillion, B. Franken, 2000

Fonte: Kolarevic (2005, pp. 38-134)

Finalmente, o sistema aditivo consiste em sobrepor camadas de material sucessivamente, até que o objeto tridimensional seja formado (VOLPATO, 2007). Para isso o software precisa criar fatias horizontais do modelo digital, que são impressas, solidificadas ou cortadas, e coladas umas sobre as outras. Pode ser subdividido de acordo com o tipo de material que utiliza: (1) sólidos (3DP - impressão 3D, SLS - sinterização seletiva a laser, FDM 


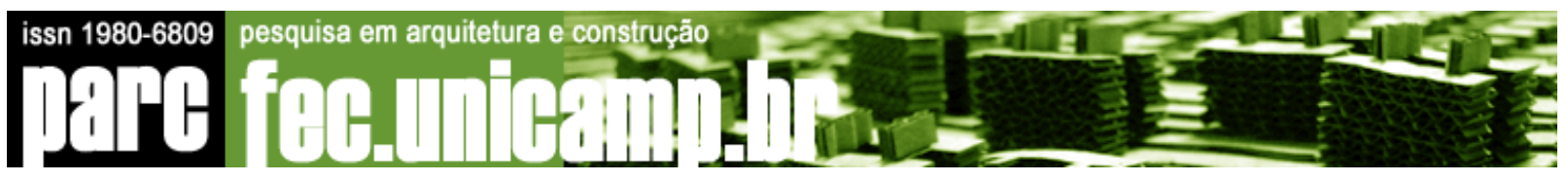

- Fusion Deposition Modeler), (2) líquidos (SLA - estereolitografia, PolyJet) ou (3) em lâminas (LOM - laminated-object-manufacturing) de papel ou alumínio. A FIG. 10 ilustra três métodos de impressão aditiva.

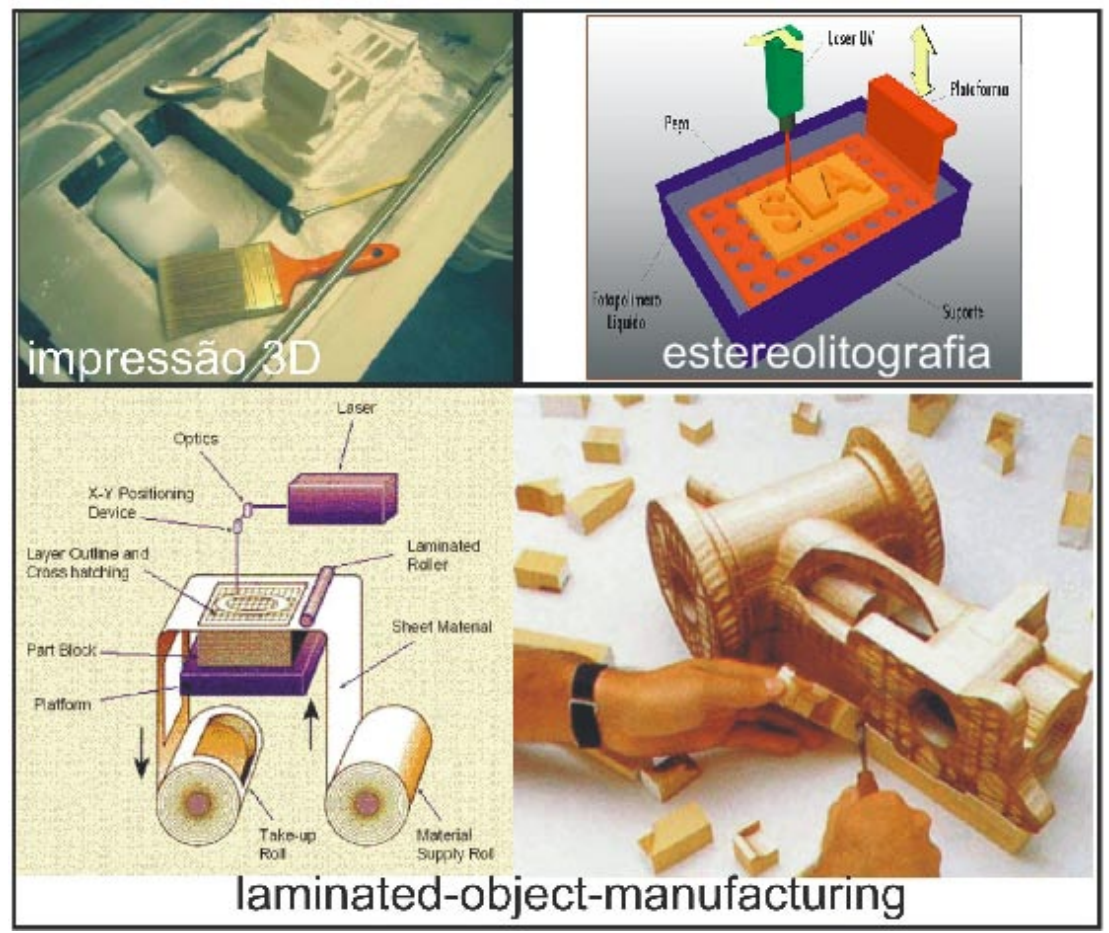

FIGURA 10: Alguns exemplos de métodos aditivos.

Fonte: http://ddf.mit.edu/devices/index.html

\section{Utilização da prototipagem rápida e fabricação digital na arquitetura e construção}

Embora já bem estabelecidas nas áreas de desenho industrial e engenharia mecânica, as aplicações da prototipagem rápida e fabricação digital na arquitetura e construção são ainda incipientes. A FIG. 11 mostra a participação da área de arquitetura dentre os diversos campos de aplicação de equipamentos de prototipagem rápida mundialmente em 2007. Segundo Wohlers (2007) as aplicações da prototipagem rápida nessa área em 2006 ainda eram insignificantes. No período entre 2006 e 2007 já foi possível notar um significativo aumento na aplicação da prototipagem rápida na arquitetura, mas em comparação com campos como a indústria automobilística, a de produtos de consumo e a área médica ela ainda é muito pequena. 

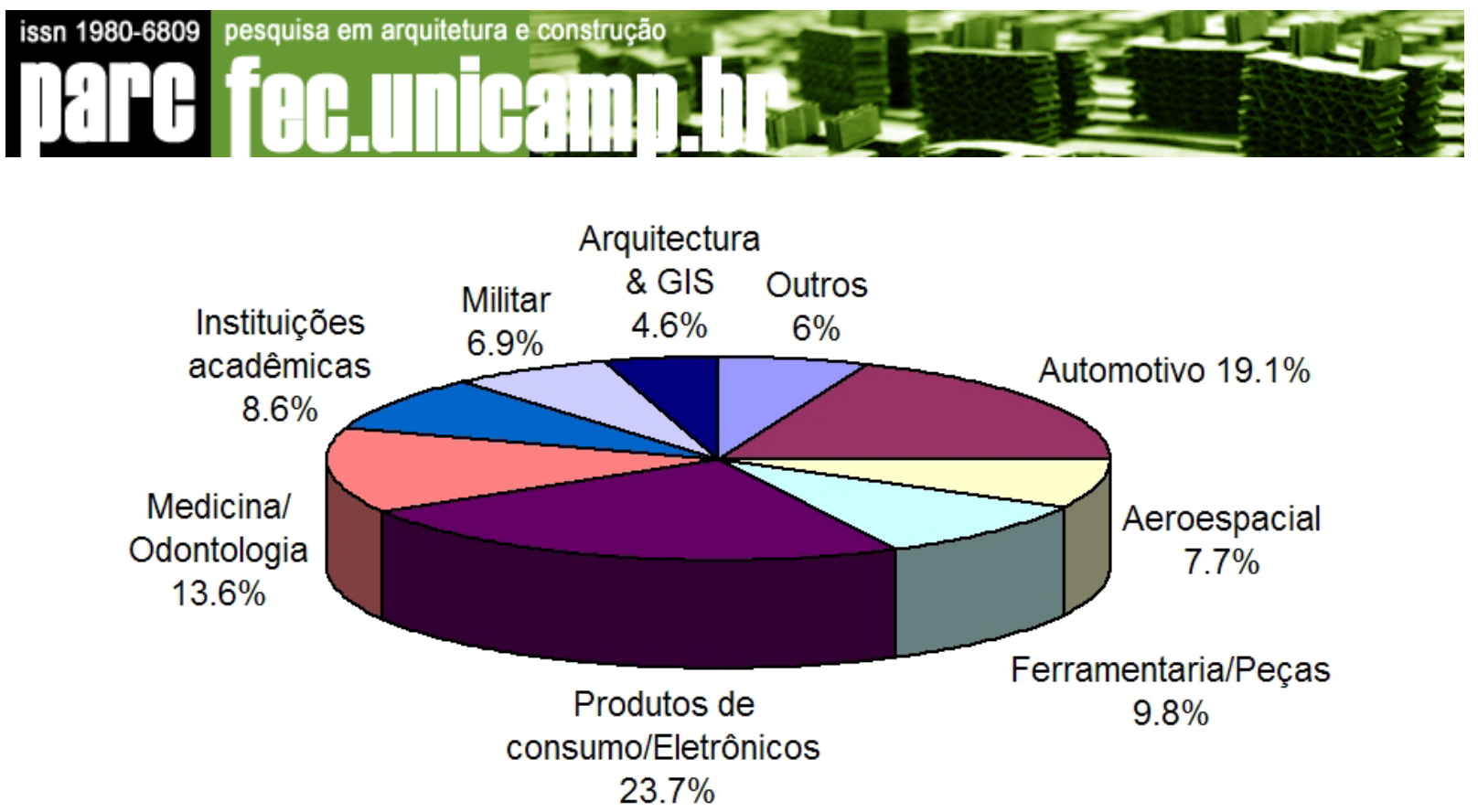

FIGURA 11: Aplicação da prototipagem rápida para a arquitetura no ano de 2007 Fonte: Wohlers Associates, 2007

Os poucos escritórios de arquitetura que adotaram recentemente o uso dessas técnicas, como Foster \& Partnes (Inglaterra), Garofalo Architects (Estados Unidos), Gehry Associates (Estados Unidos), Zaha Hadid (Inglaterra) e vêm obtendo resultados impressionantes em termos de qualidade e produtividade. A FIG. 12 mostra uma coletânea de maquetes prototipadas de projetos produzidos pelo escritório Foster \& Partners, que possui equipamentos de prototipagem rápida para uso interno, nas diversas etapas do processo de projeto.
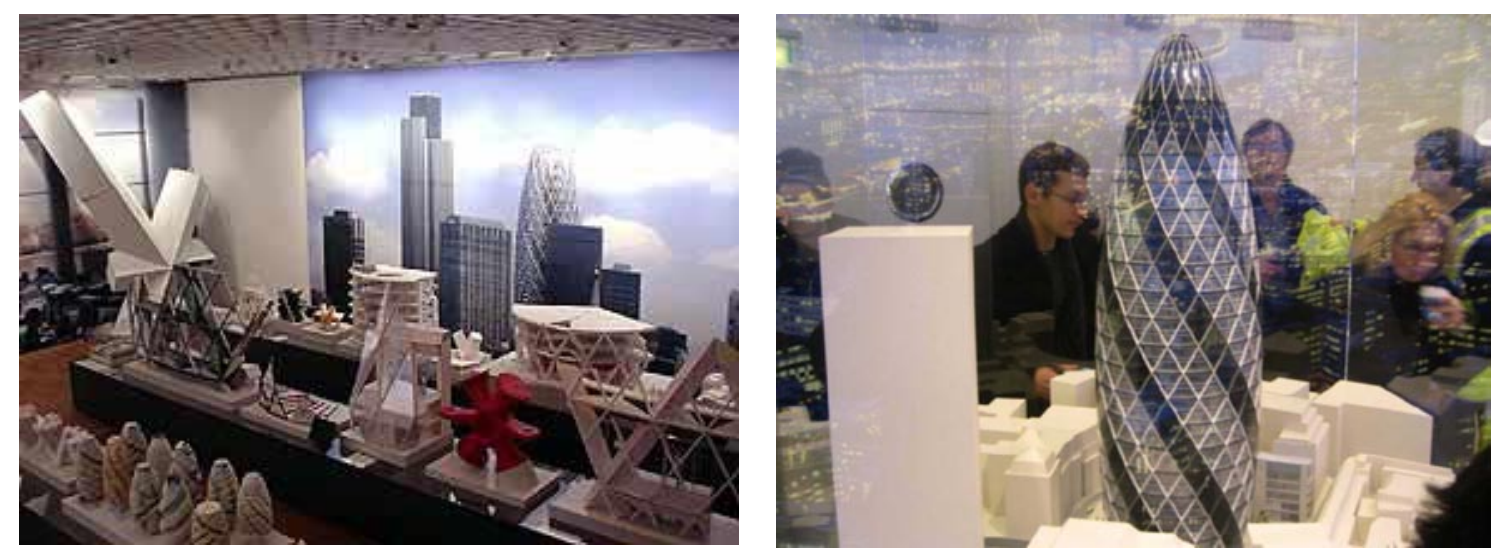

FIGURA 12: Maquetes produzidas com PR de Foster \& Partners (Londres). Fonte: http://www.arcspace.com/exhibitions/Louisiana/index.htm 


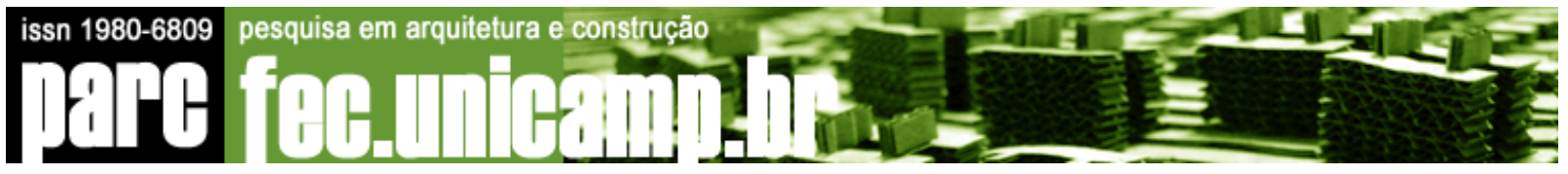

Estabelecido em Chicago, Estados Unidos, o trabalho de Douglas Garofalo, Garofalo Architects, já foi reconhecido como parte da "Nova Vanguarda", pela revista Architectual Record, devido ao esforço em aliar a fabricação digital ao processo de projeto. No exemplo ilustrado na FIG. 13, a Manilow Residence, a equipe iniciou o projeto utilizando o sistema de CAD MicroStation (Bentley) chegando à geometria final da superfície com o software de animação Maya. Depois de dimensionadas para obedecer ao tamanho das placas de madeira onde seriam cortadas, a estrutura foi exportada para um programa de "nesting", o RouterCim, que otimiza a utilização da madeira, distribuindo os componentes na área de corte da maneira mais compacta, evitando a perda de material. Depois de cortadas em uma fresa de três eixos, as peças foram então encaminhadas à obra, devidamente identificadas, para a montagem. A estrutura curva foi então recoberta com placas de madeira, coladas e parafusadas, que serviram como base para a aplicação do acabamento, membranas de titânio, em formato de losango, à prova de água.
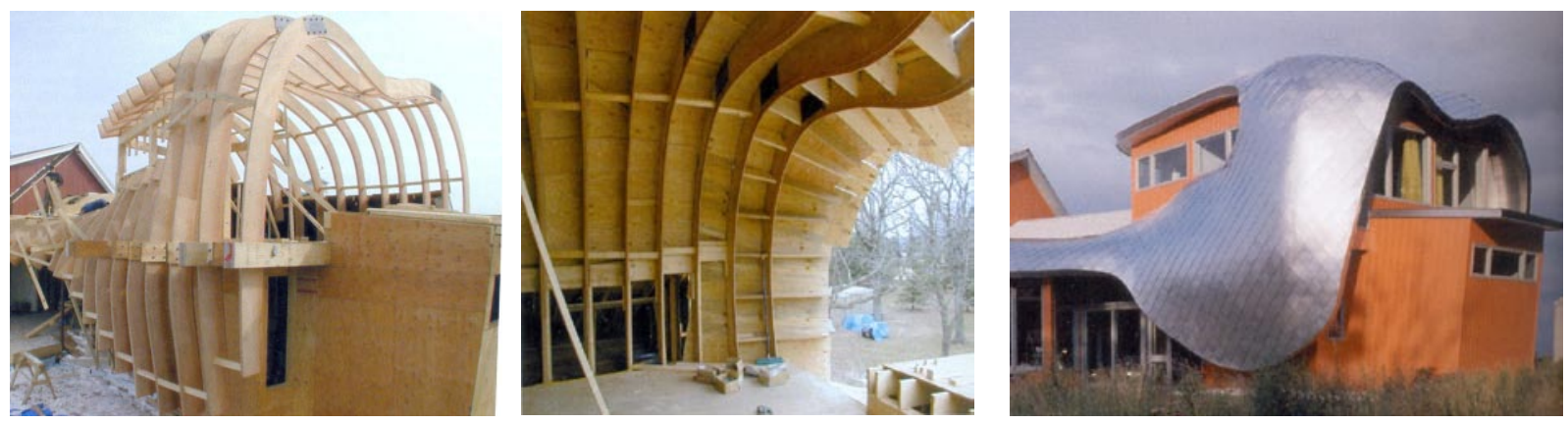

FIGURA 13: Projeto Manilow Residence, Garofalo Architects Fonte: Chaszar (2006)

O papel dos diferentes profissionais envolvidos na indústria da construção civil também está sendo modificado em conseqüência do surgimento dessas novas tecnologias. Estão surgindo novos nichos de atuação desses profissionais vinculados ao emprego das novas tecnologias. A produção e inovação do processo de projeto com a utilização dos equipamentos de prototipagem e fabricação digitais vêm renovando a maneira como o arquiteto projeta e chega ao produto final. A utilização do computational design como uma ferramenta inteligente de projeto é o direcionamento que o grupo Smart Geometry (SG) enfoca unindo prática, pesquisa e academia. Criado em 2001, o interesse do grupo varia entre o estudo do design paramétrico e a manufatura digital através de workshops e conferências. As atividades, que utilizam preferencialmente o software paramétrico Generative Components (Bentley), mostram que as ferramentas paramétricas aliadas à 


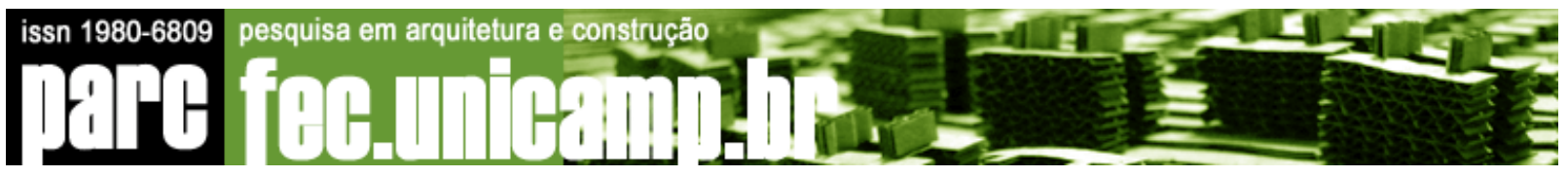

tecnologia de manufatura rápida estão colaborando para o surgimento de novas formas arquitetônicas e diferentes estruturas que estão modificando radicalmente 0 ambiente construído. Além disso, segundo Jeroen Coenders (2008), "demonstra uma evolução dos sistemas tradicionais de CAD com grandes benefícios visto que os sistemas paramétricos modelam um processo generativo onde é possível representar a lógica do projeto e o conhecimento do arquiteto de maneira explícita". A FIG. 14 ilustra alguns trabalhos do workshop intitulado "Parametric Modeling and Digital Wood Fabrication", patrocinado pelo Canadian Design Research Network e ministrado em 2007.
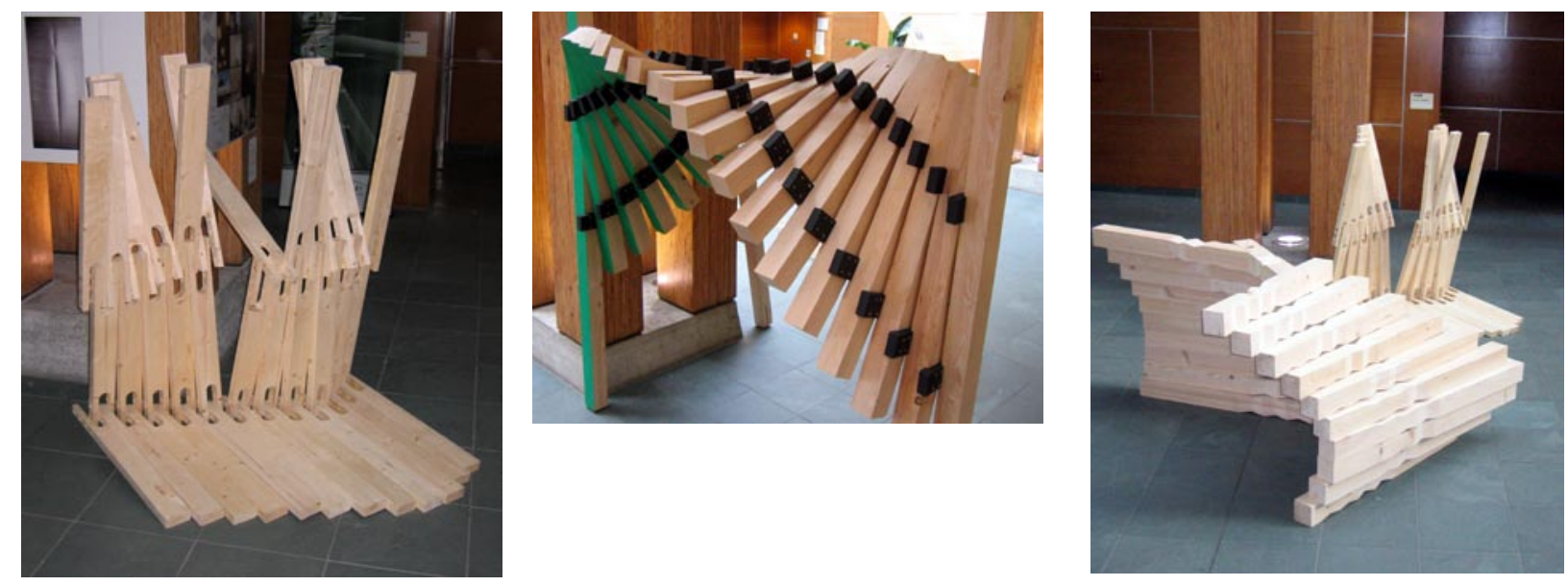

FIGURA 14: Maquetes produzidas no workshop

"Parametric Modeling and Digital Wood Fabrication" do Smart Geometry Group Fonte: http://www.smartgeometry.org

\section{Pesquisa e ensino da prototipagem rápida e fabricação digital para arquitetura e construção no Brasil}

No Brasil, a aplicação dessas técnicas na arquitetura e construção ainda é muito restrita. Isso se deve a dois fatores: um econômico e outro de ordem social. O econômico está relacionado aos altos custos dos equipamentos e insumos, que são em sua maioria importados dos Estados Unidos, da Europa e da China, embora recentemente, algumas empresas nacionais tenham começado a investir no desenvolvimento e produção de maquinário para fabricação digital. Existe também uma grande limitação social ao emprego das técnicas de fabricação digital na área de arquitetura e construção no Brasil, pois ainda não existe disponibilidade de mão de obra especializada nessa área. Além disso, 


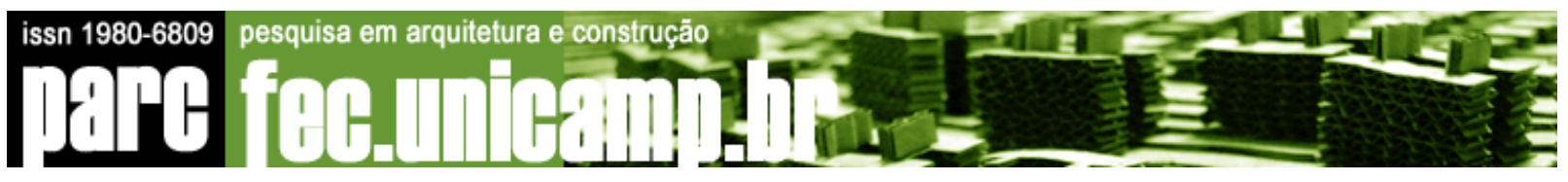

infelizmente, o ensino superior de arquitetura e de engenharia civil ainda não prevê o uso desses novos métodos na produção de maquetes, protótipos e componentes construtivos.

Em pesquisa realizada na base de dados do Diretório dos Grupos de Pesquisa no Brasil do CNPq, pôde-se constatar que existem apenas três grupos cadastrados atuantes na área de prototipagem rápida e/ou fabricação digital aplicadas diretamente à arquitetura e/ou construção civil. As palavras-chave utilizadas na busca foram: (1) prototipagem rápida, (2) fabricação digital, (3) CAD, (4) CAD-CAM e (5) arquitetura, e os resultados da pesquisa são apresentados na TAB. 1.

\begin{tabular}{|c|c|c|c|c|c|c|}
\hline $\begin{array}{l}\text { Grupo de } \\
\text { pesquisa }\end{array}$ & $\begin{array}{l}\text { Ano de } \\
\text { formação }\end{array}$ & Instituiç̧ão & Unidade & $\begin{array}{l}\text { Líder do } \\
\text { Grupo }\end{array}$ & $\begin{array}{l}\text { Linhas de } \\
\text { Pesquisa }\end{array}$ & Objetivos \\
\hline $\begin{array}{l}\text { Laboratório de } \\
\text { Estudos } \\
\text { Computacionai } \\
\text { s em Projeto }\end{array}$ & 2000 & UNB & $\begin{array}{l}\text { FAU } \\
\text { Depto. } \\
\text { Projeto }\end{array}$ & $\begin{array}{l}\text { Neander } \\
\text { Furtado } \\
\text { Silva }\end{array}$ & $\begin{array}{l}\text { •Prototipagem } \\
\text { Rápida } \\
\text { ○ Fabricação } \\
\text { Digital }\end{array}$ & Não especificados. \\
\hline $\begin{array}{l}\text { Arquitetura, } \\
\text { processo de } \\
\text { projeto e } \\
\text { análise digital }\end{array}$ & 2005 & Mackenzie & $\begin{array}{l}\text { FAU } \\
\text { Depto. } \\
\text { Projeto }\end{array}$ & $\begin{array}{l}\text { Wilson } \\
\text { Florio }\end{array}$ & $\begin{array}{l}{ }^{\circ} \text { Análise digital } \\
\text { de obras de } \\
\text { arquit. moderna } \\
\text { e } \\
\text { contemporânea }\end{array}$ & $\begin{array}{l}\text { Analisar obras de } \\
\text { arquitetura por } \\
\text { meio de modelos } \\
\text { tridimensionais, } \\
\text { simulações digitais } \\
\text { e prototipagem } \\
\text { rápida. }\end{array}$ \\
\hline $\begin{array}{l}\text { Teorias e } \\
\text { tecnologias } \\
\text { contemporâne } \\
\text { as aplicadas } \\
\text { ao projeto } \\
\text { (Laboratório } \\
\text { de Automação } \\
\text { e } \\
\text { Prototipagem } \\
\text { para } \\
\text { Arquitetura e } \\
\text { Construção) }\end{array}$ & 2006 & UNICAMP & $\begin{array}{l}\text { FEC } \\
\text { Depto. } \\
\text { Arq. e } \\
\text { Constr. }\end{array}$ & $\begin{array}{l}\text { Gabriela } \\
\text { Celani }\end{array}$ & $\begin{array}{l}\text { • Prototipagem } \\
\text { rápida } \\
{ }^{\circ} \text { Fabricação } \\
\text { digital } \\
\text { • Digitalização } \\
\text { 3D }\end{array}$ & $\begin{array}{l}\text { Estudar as } \\
\text { aplicações da } \\
\text { digitalização 3D, } \\
\text { prototipagem } \\
\text { rápida e fabricação } \\
\text { digital no processo } \\
\text { de projeto em } \\
\text { arquitetura, da } \\
\text { concepção à } \\
\text { execução da obra. }\end{array}$ \\
\hline
\end{tabular}

No início de 2007, com o auxílio da FAPESP, a Faculdade de Engenharia Civil, Arquitetura e Urbanismo (FEC) da Universidade Estadual de Campinas (UNICAMP) criou 0 LAPAC - Laboratório de Prototipagem e Automação para Arquitetura e Construção. O LAPAC (www.fec.unicamp.br/ lapac) está equipado com uma impressora 3D (Z Corp 130) e uma cortadora a laser (Universal Laser Systems X660), e acaba de obter verba da CAPES para adquirir uma fresa de controle numérico de grande formato $(1,80 \times 2,80 \mathrm{~m})$, o que permitirá a realização de protótipos de elementos construtivos em escala 1:1. 


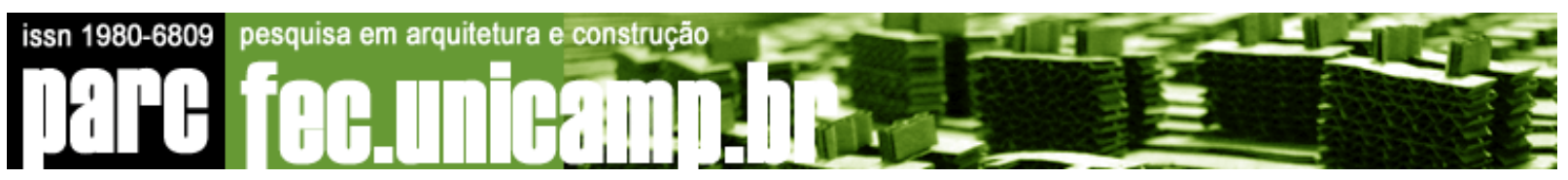

Em março de 2008 foram ministrados seis workshops nas dependências do LAPAC (FIG. 15), totalizando 56 participantes, entre alunos do último ano do curso de Arquitetura, alunos da pós-graduação e professores da FEC. Com carga horária de 8 horas cada workshop, as atividades se dividiram entre teoria e prática da prototipagem rápida para a arquitetura. O formato de workshops possibilitou que os participantes tivessem, primeiramente, uma abrangência teórica, com o estado da arte da prototipagem rápida e da fabricação digital para arquitetura hoje, e posteriormente prática, que incluiu a elaboração de exercícios e impressão nos equipamentos disponíveis no LAPAC, uma impressora 3D, ZCorp 310 e uma cortadora a laser, da Universal Laser Systems. Os objetivos principais dessa forma de abordagem foram: (1) a integração das novas tecnologias ao processo de projeto e (2) o desenvolvimento de novo conhecimento orientado para novas soluções arquitetônicas e construtivas. Neste artigo, somente serão relatadas as experiências dos workshops ocorridas com a impressora 3D - ZCorp.

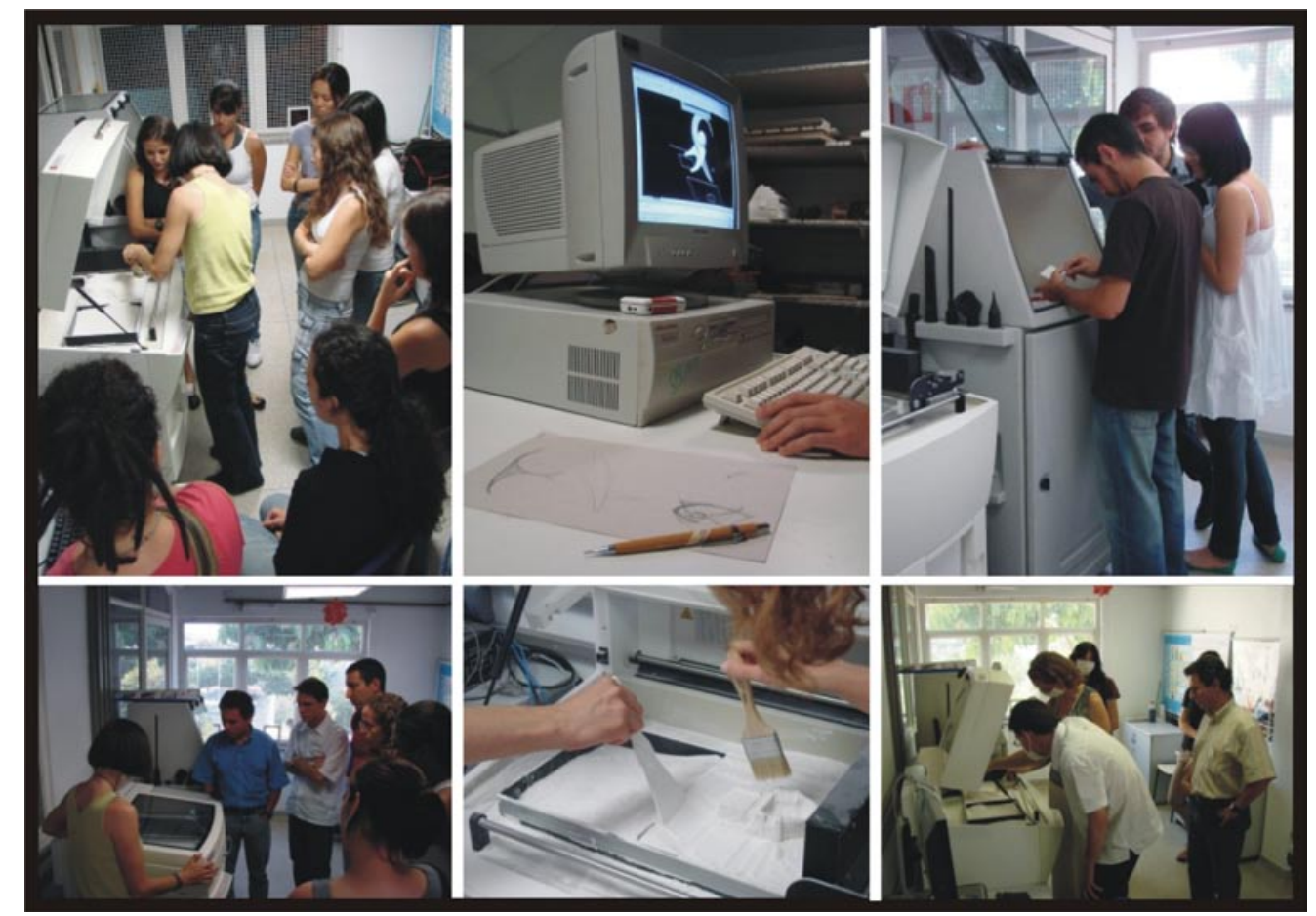

FIGURA 15: Workshops do LAPAC Fotos: Regiane Pupo

Nos exercícios práticos executados durante os workshops, destinados à impressão 3D, os alunos foram instruídos a "desafiar" a máquina. Para a impressão 3D, na máquina ZCorp 


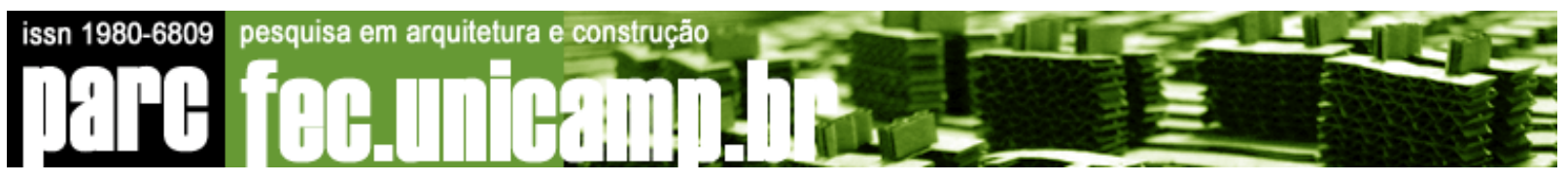

310, as instruções eram: (1) poderiam gerar suas idéias de modo intuitivo e abstrato, dentro das dimensões mínimas de tamanho e espessura permitidas pelo equipamento, já previamente discutidas, ou (2) poderiam utilizar algum projeto já existente, construído, e de difícil construção, para uma modelagem conceitual. Os softwares disponíveis para esta etapa foram o AutoCAD 2005 e o Rhinoceros R4. Foi muito interessante como os grupos discutiam o processo de modelagem e impressão tridimensional visando maior aproveitamento de material, tempo de impressão, sustentabilidade e robustez da peça durante a sua concepção. A FIG. 16 mostra dois exemplos de exercícios onde a abstração foi a linha central da criação do objeto a ser impresso tridimensionalmente.
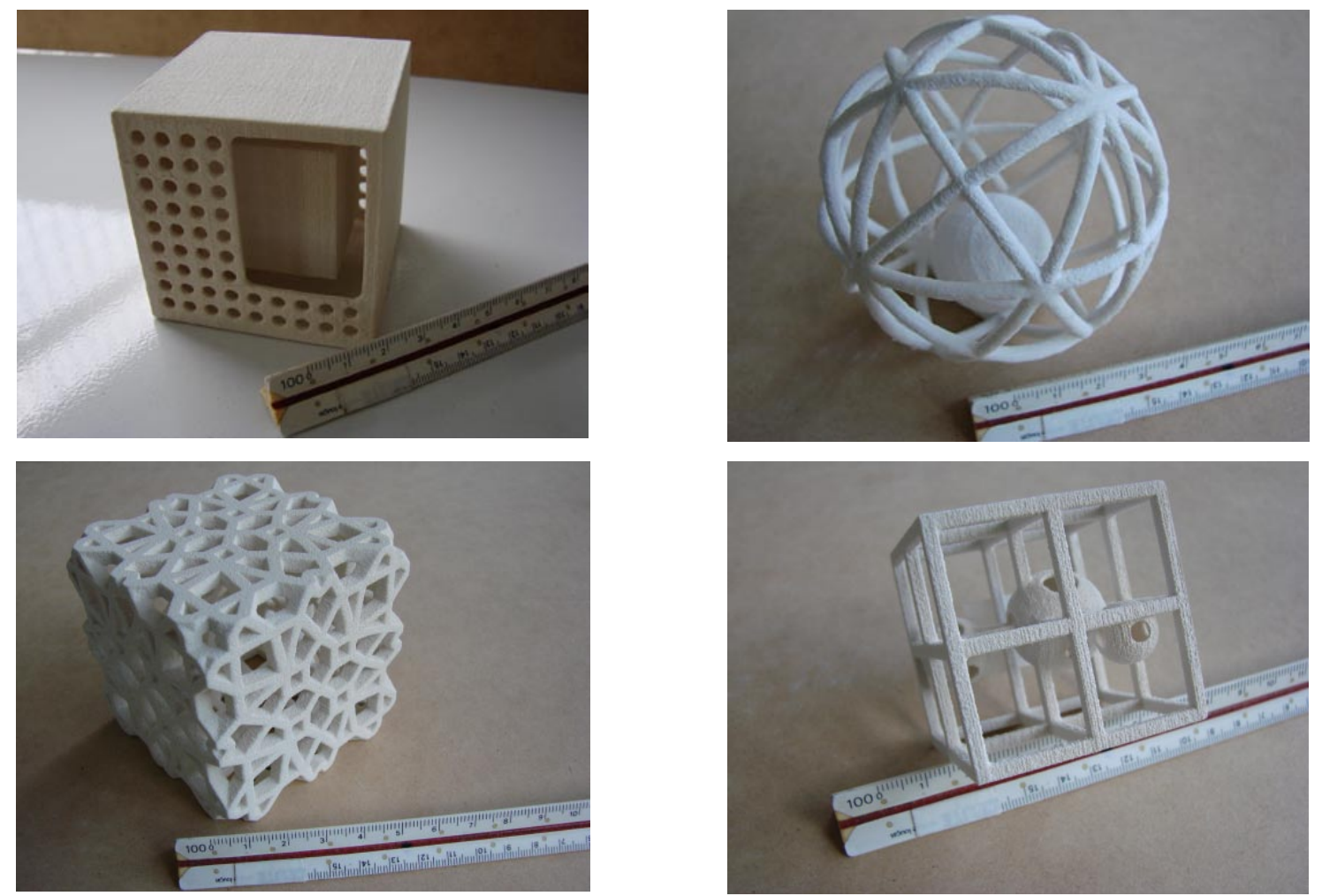

FIGURA 16: Exercícios prototipados na ZCorp

Fotos: Regiane Pupo

Da mesma forma, mas com uma abordagem mais perto da realidade do espaço construído, dois grupos desafiaram a modelagem e a impressão 3D modelando dois projetos já existentes: (1) a catedral de Brasília (1958-1970), de Oscar Niemeyer e (2) a igreja em Atlântida, Uruguai (1958), de Eladio Dieste. Respectivamente, as FIGS. 17 e 18 mostram os dois projetos construídos e suas maquetes produzidas na impressora 3D, durante 0 workshop. 


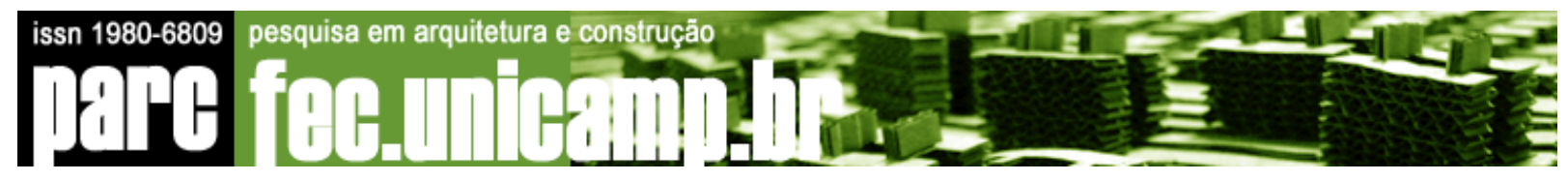

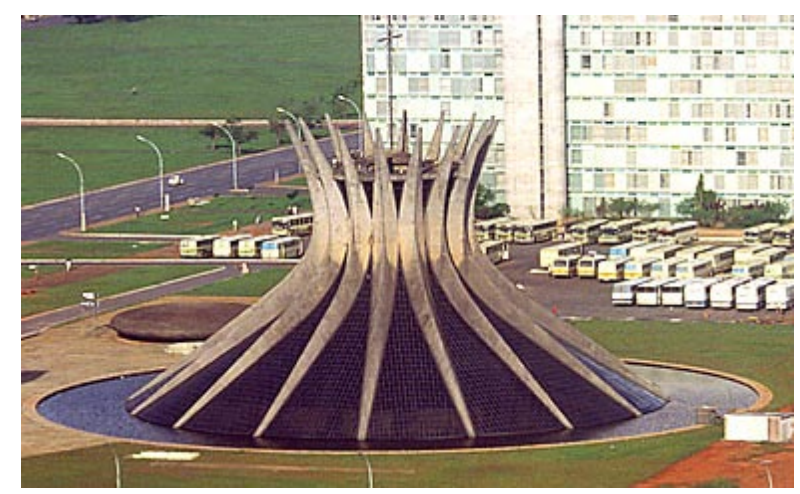

FIGURA 17: Catedral de Brasília Arquiteto Oscar Niemeyer

Fonte:http://www.geocities.com/TheTropics/3416/ photo catedral 1988.htm

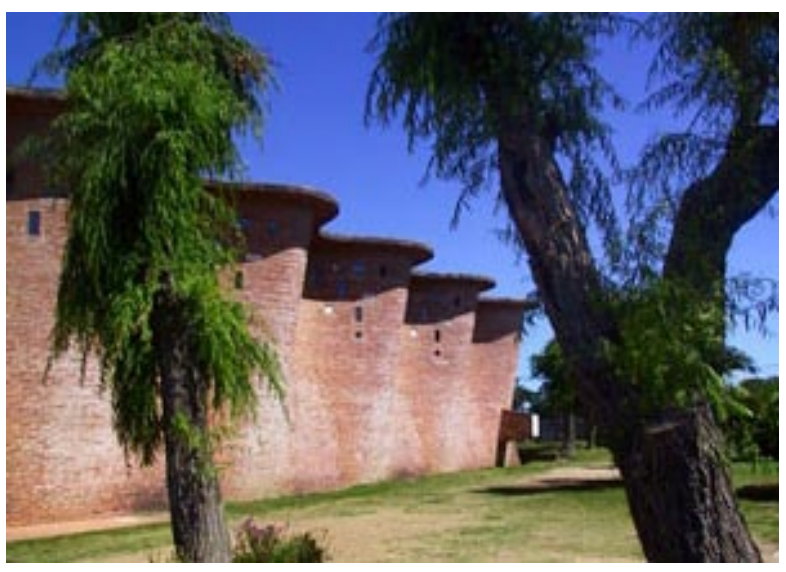

FIGURA 18: Igreja em Atlântida,Uruguai Eng. Eladio Dieste,

Fonte:http://www.vitruvius.com.br/arquitextos larq000/esp470.asp

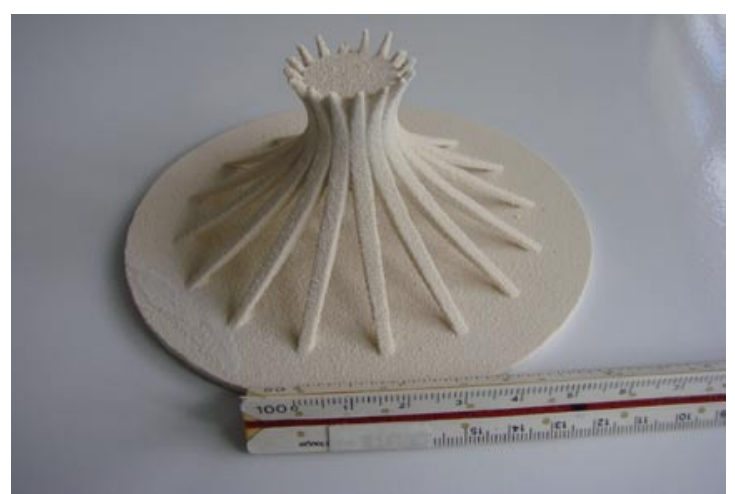

Peça prototipada em gesso - ZCorp 310 Alunos: Izabella Maciel e Renan Torricelli Foto: Regiane Pupo

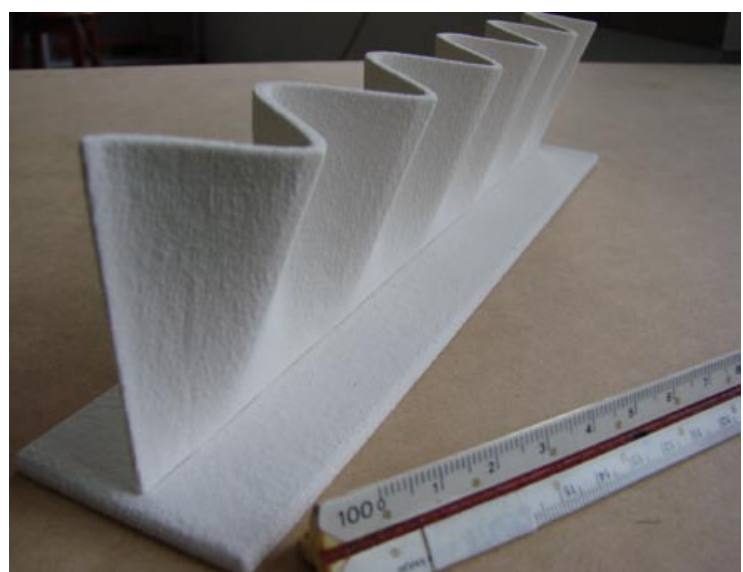

Peça prototipada em gesso - ZCorp 310 Aluna: Beatriz Andreotti Foto: Regiane Pupo

\section{Discussão}

Felizmente, a troca de informações entre os meios de representação e de produção em arquitetura e construção não desapareceram na era digital. Se o arquiteto conhecer a disponibilidade de equipamentos de fabricação digital e sua capacidade de produção, poderá projetar especificamente para estas máquinas. A conseqüência dessa troca de informação é o envolvimento dos arquitetos nos processos de fabricação (KOLAREVIC, 2003), o que demonstra que a fabricação digital pode oferecer novas oportunidades de projeto, de soluções e de fabricação de maquetes e elementos construtivos. Mitchell (apud KOLAREVIC, 


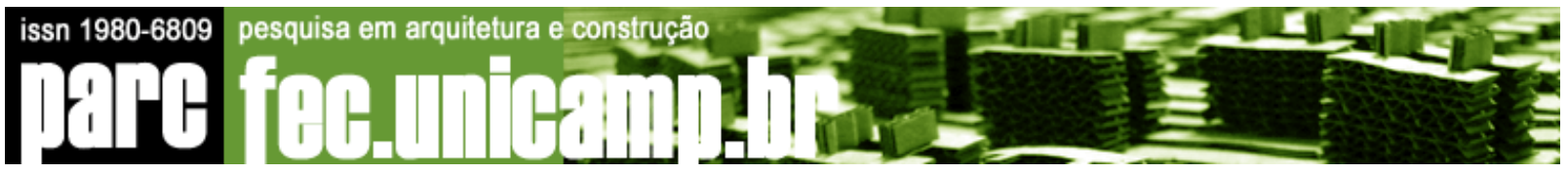

2003, pp. 32) observa que nos tempos sem tecnologia apropriada, "os arquitetos desenhavam o que podiam construir e construíam o que podiam desenhar".

Este artigo se propôs a apresentar um resumo da atual situação no Brasil da pesquisa na área de novas tecnologias digitais para a arquitetura e construção que vão além da simples representação. Foi possível constatar que ainda são poucos os grupos de pesquisa que atuam nessa área, apesar da grande relevância do tema. É papel da universidade introduzir essas novas tecnologias no ensino e na pesquisa, de maneira que os jovens arquitetos estejam preparados para lidar com a uma nova realidade profissional, na qual a tecnologia está presente cada vez mais nas diversas etapas do projeto. A idéia fundamental é o beneficio educacional que esse tipo de workshop ministrado pelo LAPAC proporciona. Espera-se que não somente de equipamentos sofisticados e de software poderosos seja possível alcançar bons resultados na formação de arquitetos. Também o desenvolvimento cuidadoso das etapas de projeto e um cronograma para o desenvolvimento de ciclos são necessários para que se obtenham produtos finais criativos e competitivos.

No exterior, as aplicações da prototipagem rápida e fabricação digital na arquitetura e construção tiveram como um de seus pioneiros William Mitchell, do MIT. No livro Digital Design Media, de 1995, Mitchell e McCullough descrevem diversas aplicações na arquitetura, ilustradas por casos reais em projetos de Frank O. Gehry. Desde então os cursos de arquitetura das principais universidades americanas e européias vêm disponibilizando para seus alunos e pesquisadores laboratórios equipados com diferentes técnicas de prototipagem rápida e fabricação digital. Alguns exemplos são o Digital Design Fabrication Group do Massachusetts Institute of Technology (ddf.mit.edu), o I-made da Ball State University (ww.bsu.edu/imade), o Architecture and Digital Fabrication da Swiss Federal Institute of Technology in Zurich (www.dfab.arch.ethz.ch) e o CAMLab da Delft University of Technology (www.bk.tudelft.nl/live/pagina.jsp?ide=0681ceeb-180e-42a9-8a08-1905b377c130\&lang=nl).

A página de abertura do site do laboratório Architecture and Digital Fabrication da ETHZ, um dos centros de pesquisa mais proeminentes nessa área, afirma que "o desenvolvimento tecnológico das últimas décadas está tendo um efeito fundamental nas condições de produção da arquitetura. Ele influencia a maneira como a arquitetura é concebida e implementada." Este é um assunto que sem dúvida deverá ser levado em conta pelos cursos de arquitetura nos próximos anos. 
Agradecimentos

A autora agradece à professora Gabriela Celani pela orientação da tese de doutorado e à FAPESP pelo apoio a esta pesquisa.

\section{Referências}

BUSWELL, R.; SOAR R.; GIBB A.; THORPE A. Freeform Construction: Mega-scale Rapid Manufacturing for construction. In: Automation in Construction 16, 2007, p.224-231.

DAVIS, S. Future Perfect. Harlow: Addison-Wesley Pub Co, 1996.

CHASZAR, A. Blurring the Lines. Grã Bretanha: Wiley-Academy, 2006.

CNPq, Diretório dos Grupos de Pesquisa no Brasil. Disponível em: www.dgp.cnpq.br/buscaoperacional. Acesso em 25 de abril de 2008.

DUARTE, J.P. Customizing Mass Housing: a discursive grammar for Siza's houses at Malagueira. Tese de doutorado, Massachusetts Institute of Technology, 2001.

KHOSHNEVIS, B. Automated construction by contour crafting - related robotics and information technologies. Automation in constrution, 2004. v.13, n.2, p. 05-19.

KOLAVERIC, B. Architecture in the Digital Age: Design and Manufacturing. Oxford: Taylor \& Francis, 2005. 314 p. ISBN 0-415-27820-1.

MARK, E.; MARTENS, B.; OXMAN, R. The Ideal Computer Curriculum. In: Anais do 19 eCAADe, 2000. pp. 168-175

MITCHELL, W.; McCULLOUGH M. Digital Design Media. N. York: Van Nostrand Reinhold, 1995.

PINE, B. J. Mass Customization - The New Frontier in Business Competition. Boston, Mass.: Harvard Business School Press, 1993.

SCHAMAL, P. Digital Real. Basel: Birkhauser, 2001.

SCHODEK, D. et al. Digital Design and Manufacturing. New Jersey: John Wiley and sons, 2005.

Smart Geometry Group, http://www.smartgeometry.org./node/70,

TSENG, M.M.; JIAO, J. Mass Customization. In: Handbook of Industrial Engineering, Technology and Operation Management (3rd ed.), 2001.

VOLPATO, N. Prototipagem Rápida: Tecnologias e Aplicações. São Paulo: Edgard Blucher, 2007.

WOHLERS, T. T .Wohlers report 2007. Fort Collins, Colorado: Wohlers Associates, 2007. 